\title{
Proposal for a new evaluation of phagocytosis using different sizes of fluorescent polystyrene microspheres
}

\author{
Riyo Enomoto ${ }^{1,2}$, Makoto Imamori ${ }^{1}$, Ayoumi Seon ${ }^{1}$, Kozue Yoshida ${ }^{1}$, Aya Furue ${ }^{1}$, Hirofumi Tsuruda ${ }^{1}$, \\ Eibai Lee-Hiraiwa ${ }^{1,2^{*}}$ \\ ${ }^{1}$ Laboratory of Pharmacology, Faculty of Pharmaceutical Sciences, Kobe Gakuin University, Kobe, Japan \\ ${ }^{2}$ Cooperative Research Center of Life Sciences, Kobe Gakuin University, Kobe, Japan \\ Email: "elee@pharm.kobegakuin.ac.jp
}

Received 25 September 2013; revised 26 October 2013; accepted 18 November 2013

Copyright (C) 2013 Riyo Enomoto et al. This is an open access article distributed under the Creative Commons Attribution License, which permits unrestricted use, distribution, and reproduction in any medium, provided the original work is properly cited

\section{ABSTRACT}

To investigate phagocytosis, peritoneal-resident and J774.1 macrophages were incubated with fluorescent polystyrene microspheres measuring $1.0 \mu \mathrm{m}$ in diamter at 200 particles per cell. The amount of phagocytized microspheres increased with incubation time, and both cell types had similar phagocytic activity. Further, we investigated the phagocytosis of different sizes of microspheres by J774.1 macrophages. To adequately evaluate phagocytosis, varying amounts of different sizes of microspheres were added to $\mathbf{J 7 7 4 . 1}$ cells, and their phagocytic activities were evaluated. When the microspheres were added at a density of 20 particles per cell, few small microspheres $(<1.0 \mu \mathrm{m}$ in diameter) were phagocytized. This result suggested that their low amount caused difficulty in evaluating phagocytosis. In contrast, when the same variety of microspheres was added at a density of 200 particles per cell, phagocytosis of large microspheres $(>3 \mu \mathrm{m}$ in diameter) could not be evaluated because of cytotoxicity. Thus, the amount of different sizes of microspheres added is important for precisely evaluating phagocytic activity. When the amount of different sizes of microspheres added was standardized to provide a set amount of total surface area, phagocytosis of these microspheres could be adequately evaluated and compared. To determine the effects of phagocytosis on cell viability and proliferation, cells incubated with different sizes of microspheres were assayed using a cell counting kit. We found that phagocytosis had no effect on cell viability or proliferation and was independent of particle size. Furthermore, cells already phagocytized microspheres retained their phagocytic activity.

"Corresponding author.
Keywords: Macrophage; Phagocytosis; Polystyrene Microsphere; Total Surface Area

\section{INTRODUCTION}

Dying cells [1-5] or foreign materials [6] are rapidly removed in vivo, both by neighboring tissue cells and professional phagocytes such as macrophages and dendritic cells. Recently, micron-, submicron-, and nanoscale particles composed of various materials have been used as delivery devices for living cells or tissues. Most of these artificial particles are also phagocytized by macrophages present in tissues or organs throughout the body $[7,8]$, especially, particles with a negative charge are recognized via scavenger receptors and phagocytized by macrophages.

Phagocytosis by macrophages has often been investigated using fluorescent polystyrene microspheres. Macrophage activity is generally evaluated by measuring the number of phagocytized microspheres. Because the number of microspheres phagocytized increases in proportion to the number added to cultures, experimental conditions are very important in accurately evaluating phagocytic activity. However, currently, researchers set their own original criteria for the addition of microspheres and evaluation of phagocytosis because no standardized conditions for such assays have been determined. This situation complicates the interpretation and comparison of related data in many reports concerning phagocytosis. Currently, microspheres are often added in any amount or weight per culture area for the evaluation of phagocytosis, but these conditions are presumably unsuitable for the addition of extremely large or small microspheres or those having different specific gravities. The recent developments of new materials and nano-scale technologies are key components in the field of delivery devices. Thus, new standardized conditions that are 
widely applicable are necessary for the evaluation of phagocytosis. Thus, in this study, we developed new standardized conditions for the addition of microspheres. Furthermore, we assessed cell viability and cell activity of macrophages after phagocytosis using these standardized conditions.

\section{MATERIALS AND METHODS}

\subsection{Microsphere}

Various sizes of Fluoresbrite ${ }^{\circledR}$ yellow-green fluorescent polystyrene microspheres were purchased from Polysciences Inc. (Warrington, PA). FluoSphere ${ }^{\circledR}$-red fluorescent 1.0- $\mu \mathrm{m}$ microspheres were purchased from Molecular probes/Life Technologies (Grand Island, NY). Diameter coefficient of variation (CV) of each microsphere was $3 \%$ to $10 \%$. All experiments were conducted with carboxylate-modified microspheres.

\subsection{Cell Culture}

Peritoneal resident macrophages were harvested from 12-14-week-old female Wistar rats and suspended in RPMI 1640 medium (Nacalai Tesque, Kyoto, Japan) supplemented with $10 \%$ fetal bovine serum (FBS) (Biowest, Tokyo, Japan). J774.1 macrophages were maintained in in $100-\mathrm{mm}$ plastic dishes containing the same medium. When the cells reached $70 \%-80 \%$ confluence, they were subcultured and passaged into new 12- or 96-well plastic plates or chamber slides and precultured at $37^{\circ} \mathrm{C}$ in an atmosphere of $5 \% \mathrm{CO}_{2}$ in air.

\subsection{Addition of Microspheres to Macrophages}

The cells were plated into 12 -well plates $\left(8 \times 10^{4}\right.$ cells/ well) and pre-cultured for 2 days (until $70 \%-80 \%$ confluent, approximately $2 \times 10^{5}$ cells/well). The microspheres were suspended in RPMI 1640 medium containing $10 \% \mathrm{FBS}$, and the suspension was added to the cells. We evaluated phagocytosis using $1.0 \mu \mathrm{m}$ microspheres $\left(4 \times 10^{7}\right.$ particles/well, 200 particles per cell). When we measured phagocytosis of other sizes of microspheres, we compensated by adjusting for total volume or total surface area in relation to the size of the microspheres and amount added. The amount of microspheres of each size added to the cells is shown in Table 1. Upper section of Table 1 shows conditions standardized for volume; the amount of microspheres of each size added was calculated so that the total volume of added microspheres of each size was equal to the total volume of $1.0 \mu \mathrm{m}$ microspheres used. Lower section of Table 1 shows conditions standardized for surface area. The amount of microspheres of each size added was calculated so that the total surface area of added microspheres of each size was equal to the total surface area of the 1.0
Table 1. Amount ratios of fluorescent microspheres to cells corrected by volume and surface area.

\begin{tabular}{cccc}
\hline Diameter $(\mu \mathrm{m})$ & Volume $\left(\pi \mu \mathrm{m}^{3}\right)$ & Factor & Cell: Microsphere \\
\hline 0.1 & 0.00017 & $\times 1000$ & $1: 200000$ \\
0.2 & 0.0013 & $\times 125$ & $1: 25000$ \\
0.5 & 0.021 & $\times 8.0$ & $1: 1600$ \\
$\mathbf{1 . 0}$ & $\mathbf{0 . 1 6 7}$ & $\times \mathbf{1 . 0}$ & $\mathbf{1 : 2 0 0}$ \\
2.0 & 1.33 & $\times 0.125$ & $1: 25$ \\
3.0 & 4.50 & $\times 0.037$ & $1: 7$ \\
6.0 & 36.0 & $\times 0.005$ & $1: 1$ \\
Diameter $(\mu \mathrm{m})$ & Surface area $\left(\pi \mu \mathrm{m}^{2}\right)$ & Factor & Cell: Microsphere \\
0.1 & 0.01 & $\times 100$ & $1: 20000$ \\
0.2 & 0.04 & $\times 25$ & $1: 5000$ \\
0.5 & 0.25 & $\times 4.0$ & $1: 800$ \\
$\mathbf{1 . 0}$ & $\mathbf{1 . 0}$ & $\times \mathbf{1 . 0}$ & $\mathbf{1 : 2 0 0}$ \\
2.0 & 4.0 & $\times 0.250$ & $1: 50$ \\
3.0 & 9.0 & $\times 0.111$ & $1: 22$ \\
6.0 & 36.0 & $\times 0.028$ & $1: 6$ \\
\hline
\end{tabular}

${ }^{*}$ We used this value as a base value.

$\mu \mathrm{m}$ microspheres used.

\subsection{Quantitative Evaluation of Phagocytosis}

The medium was removed from 12 -well plates and the fluorescent microspheres dispersed in growth medium were added to the cultured cells. The cells were incubated at $37^{\circ} \mathrm{C}$ in $5 \% \mathrm{CO}_{2}$ for indicated times. At the end of the incubation period, cells were washed twice with phosphate buffered saline (PBS) to remove free microspheres and harvested by trypsinization. The harvested cells were suspended in PBS and analyzed by flow cytometry (FACSCanto, BD Biosciences, Franklin Lakes, NJ). Flow cytometry data are shown as fluorescent sidescatter dot plots. We gated each population of cells according to the amount of microspheres engulfed, from 0 to 4 or more, and calculated the percentage of cells in each population.

\subsection{Morphological Observation of Phagocytosis}

Fluorescent microspheres were added to cells in chamber slides and incubated at $37^{\circ} \mathrm{C}$ in an atmosphere of $5 \%$ $\mathrm{CO}_{2}$ for indicated times. At the end of the incubation period, cells were washed twice with PBS to remove free microspheres. Cells on glass chamber slides were directly observed by confocal laser scanning microscopy (FV-1000D, Olympus).

\subsection{Evaluation of Cytotoxicity and Proliferation}

Cells were plated in two 96 -well plates $\left(5 \times 10^{3}\right.$ cells/ well) and pre-cultured for 2 days (until approximately $50 \%$ confluent). Different sizes of fluorescent microspheres were added to the cells in varying amounts to 
provide an equivalent total surface area. Cells were incubated at $37^{\circ} \mathrm{C}$ in an atmosphere of $5 \% \mathrm{CO}_{2}$ for $3 \mathrm{~h}$. Cells were washed twice with PBS, and fresh growth medium was added to the wells. One plate was analyzed immediately and the other was incubated at $37^{\circ} \mathrm{C}$ in an atmosphere of $5 \% \mathrm{CO}_{2}$ for a further $24 \mathrm{~h}$. Cytotoxicity and proliferation immediately and $24 \mathrm{~h}$ after phagocytosis were evaluated using Cell Counting Kit-8 (CCK8; Dojindo, Kumamoto, Japan).

\section{RESULTS AND DISCUSSION}

\subsection{Phagocytosis of Microspheres by Macrophages}

Phagocytosis involves a series of processes including binding to the cell surface and uptake by the cell. In our analysis of cells by flow cytometry, all microspheres attached to the cell surface or taken up by the cells were assumed to be phagocytized microspheres. To remove microspheres nonspecifically adsorbed to the cell surface, cell suspensions after incubation with fluorescent polystyrene microspheres were centrifuged in PBS containing $3 \%$ bovine serum albumin (BSA). Microspheres nonspecifically adsorbed to the cell surface separated from the cells due to difference in density between the free microspheres and cells. Washing in PBS/BSA solution did not affect the amount of microspheres phagocytized by cells (data not shown), but helped wash out microspheres nonspecifically adsorbed to cells. In subsequent experiments, the cells were washed with PBS. To elucidate whether or not smaller microspheres are phagocytized, $0.1-\mu \mathrm{m}$ microspheres were added to cultures of the same cells. As shown in Figure 1, both $0.1-\mu \mathrm{m}(4 \times$ $10^{9} \mathrm{particles} / \mathrm{well}, 20,000$ particles per cell) and $1.0-\mu \mathrm{m}$ $\left(4 \times 10^{7}\right.$ particles/well, 200 particles per cell $)$ microspheres were taken up by the cells.

To compare the phagocytic activity of peritoneal resident and non-stimulated J774.1 macrophages, both types of cells were incubated with $1.0 \mu \mathrm{m}$ microspheres $(4 \times$ $10^{7}$ particles/well, 200 particles per cell). Peritoneal resident and J774.1 macrophages both phagocytized microspheres and the amount of microspheres phagocytized increased with incubation time in both cell types. Since J774.1 macrophages resembled peritoneal resident macrophages in their phagocytic activity (Figure 2), we used J774.1 macrophages in subsequent experiments.

\subsection{Relation of Phagocytosis to the Amount of Microspheres Added}

Different sizes of microspheres were added to J774.1 cells $\left(4 \times 10^{6}\right.$ particles/well, 20 particles per cell), and their phagocytic activities were evaluated. Few small microspheres $(<1.0 \mu \mathrm{m}$ in diameter $)$ were phagocytized (Figure 3), suggesting that small amounts of these mi-

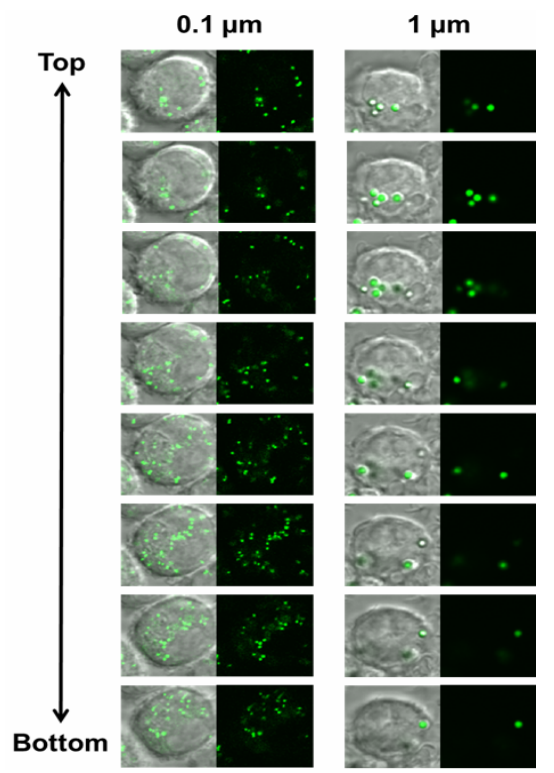

Figure 1. Phagocytosis of J774.1 macrophages incubated with different sizes of microspheres. Cells were incubated with 0.1 - or $1.0-\mu \mathrm{m}$ microspheres according to lower section of Table 1 for $1 \mathrm{~h}$. Cells phagocytizing microspheres were observed from the top (cell surface) to the bottom using a confocal laser scanning microscope. Images were acquired every $0.5 \mu \mathrm{m}$.
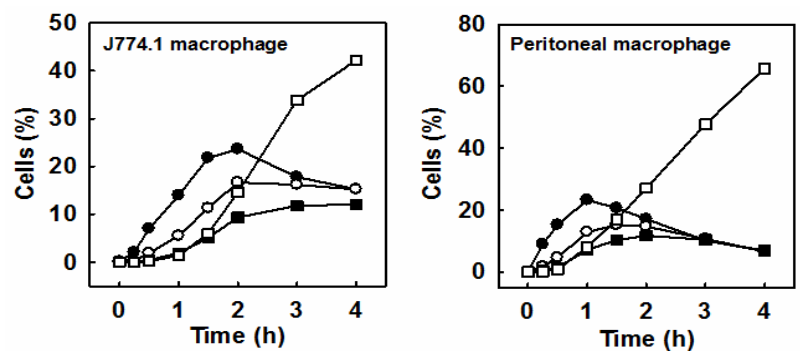

(a)
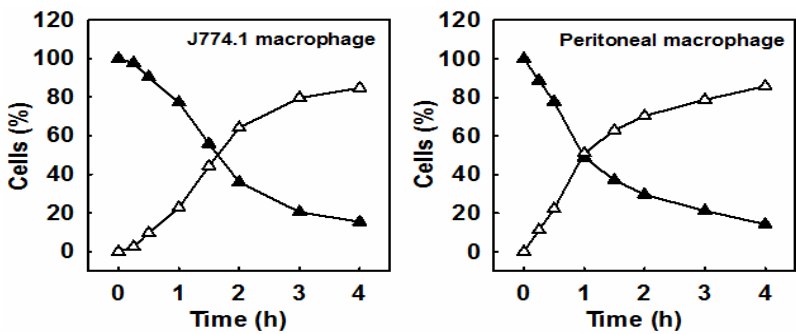

(b)

Figure 2. Comparison of phagocytosis between J774.1 macrophages and rat peritoneal macrophages. (a) Percentages of each population of macrophages were plotted. Closed circles, cells engulfing 1 microsphere; open circles, cells phagocytizing 2 microspheres; closed squares, cells phagocytizing 3 microspheres; open squares, cells engulfing four microspheres. (b) Percentages of macrophages that phagocytized microspheres were plotted. Closed triangles, cells phagocytizing nothing; open train-gle, cells phagocytizing more than 1 microsphere. 

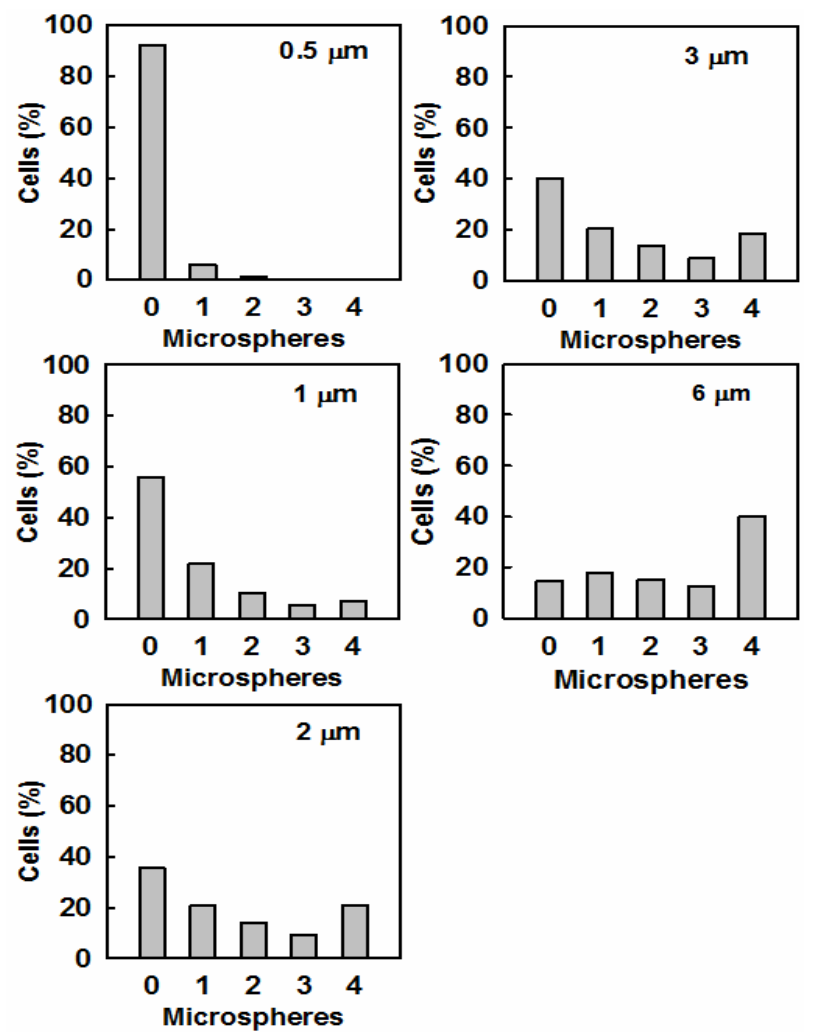

Figure 3. Effect of the amount of microspheres on phagocytosis in J774.1 macrophages. Cells were cultured in the presence of different sizes of microspheres for $3 \mathrm{~h}$. All micro-spheres were added to cells at 20 particles per cell. Cells were washed 3 times and analyzed using a flow cytometer. The data were analyzed and each population was indicated on $\mathrm{X}$-axis.

crospheres caused difficulty in evaluating phagocytosis. Therefore, we added these microspheres to the cells under different conditions $\left(4 \times 10^{7}\right.$ particles/well, 200 particles per cell) (Figure 4). The phagocytosis of microspheres less than $3.0 \mu \mathrm{m}$ in diameter was able to evaluate under this condition. But when the microspheres more than $3.0 \mu \mathrm{m}$ in diameter were added at this condition (200 particles per cell), the phagocytosis could not evaluate due to these cytotoxicity. These results suggest that the amount of microspheres added to cells in culture is important in precisely evaluating phagocytosis. To compensate for differences in the size and amount of microspheres added, microspheres of each size were added to cells as shown in Table 1. These conditions compensated for differences in the total volume or total surface area of microspheres, and results revealed that the phagocytic activity of cells decreased as the size of the microspheres increased (Figures 5 and 6). Since cells that engulfed microspheres of less than $0.5-\mu \mathrm{m}$ diameter could not be separated from the remaining cell population, data are shown as dot plots (Figures 5(b) and 6(b)). Among all sizes of microspheres added according to upper section of Table 1, phagocytosis of microspheres of less than 1.0 $\mu \mathrm{m}$ was very high (Figure 5). This phenomenon may be caused by the addition of too many microspheres. In contrast, few microspheres over $4.5-\mu \mathrm{m}$ diameter were phagocytized (Figure 5(a)). However, these results suggest that the amount of microspheres is insufficient to evaluate phagocytosis. Particles are generally added to cells as voluntary weight per culture area or per fluid volume in a phagocytic assay. We consider that this method is suitable for the addition of particles of equal specific gravity. However, appropriate correction is necessary when the particles added are of different sizes, specific gravities, or composed of different materials. Among all sizes of microspheres added according to lower section of Table 1, phagocytosis of all sizes of microspheres could be evaluated (Figure 6). Since phagocytosis begins with the interaction between the surfaces of the microspheres and the cell surface, compensation for total surface area (lower section of Table 1) appears to be a better method of compensating for the variable amounts of microspheres in a phagocytic assay. In subsequent experiments, microspheres were added in appropriate amounts to provide the same total surface area.

\subsection{Effects of Phagocytosis on Cell Viability and Cell Function}

To elucidate whether or not the phagocytized microspheres had deleterious effects on J774.1 macrophages, cell viability and proliferation were determined. The intracellular microspheres had no effect on cell viability or proliferation regardless of microsphere size (Figure 7(a)). Next, the phagocytic activity of cells having phago-

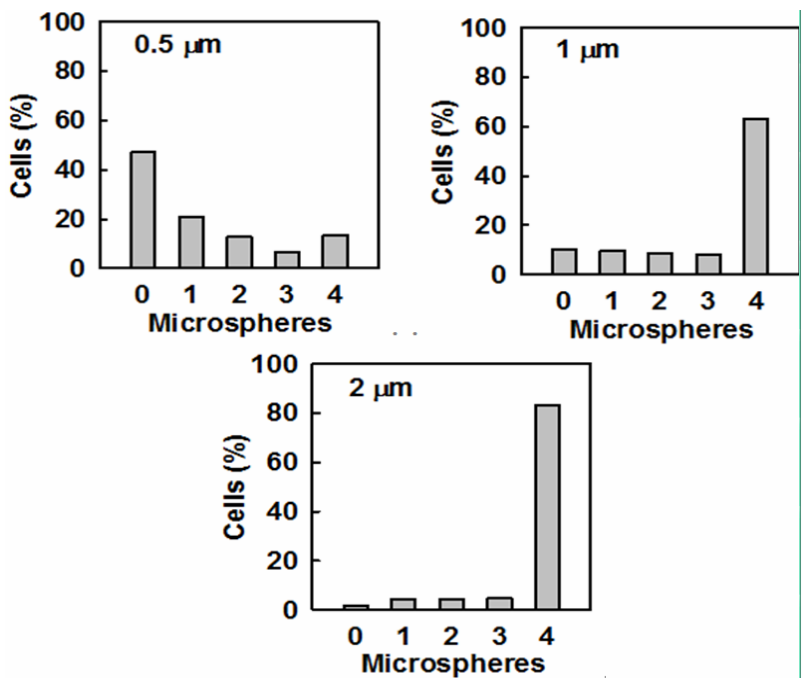

Figure 4. Effect of the amount of microspheres on phagocytosis in J774.1 macrophages. Cells were cultured in the presence of different sizes of microspheres for $3 \mathrm{~h}$. All microspheres were added to cells at 200 particles per cell. Cells were washed 3 times and analyzed using a flow cytometer. The data were analyzed and each population was indicated on X-axis. 

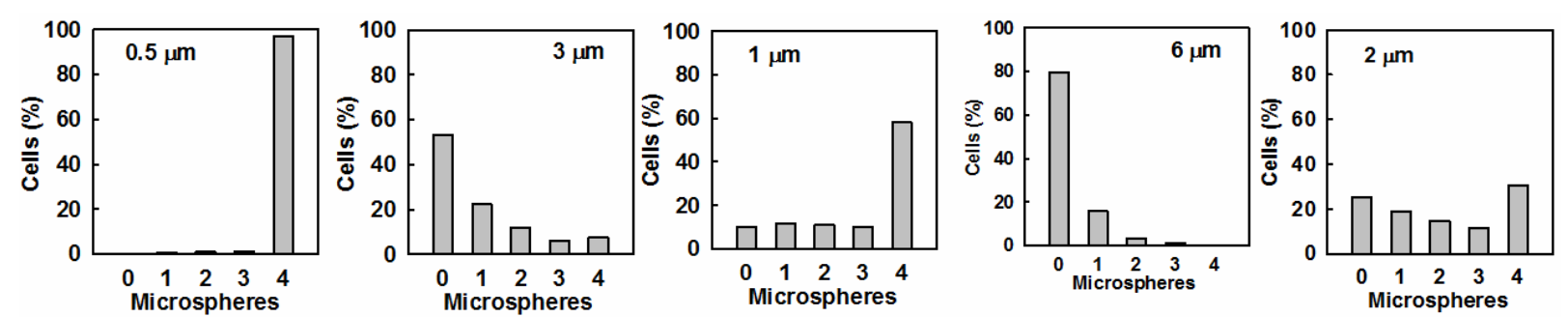

(a)
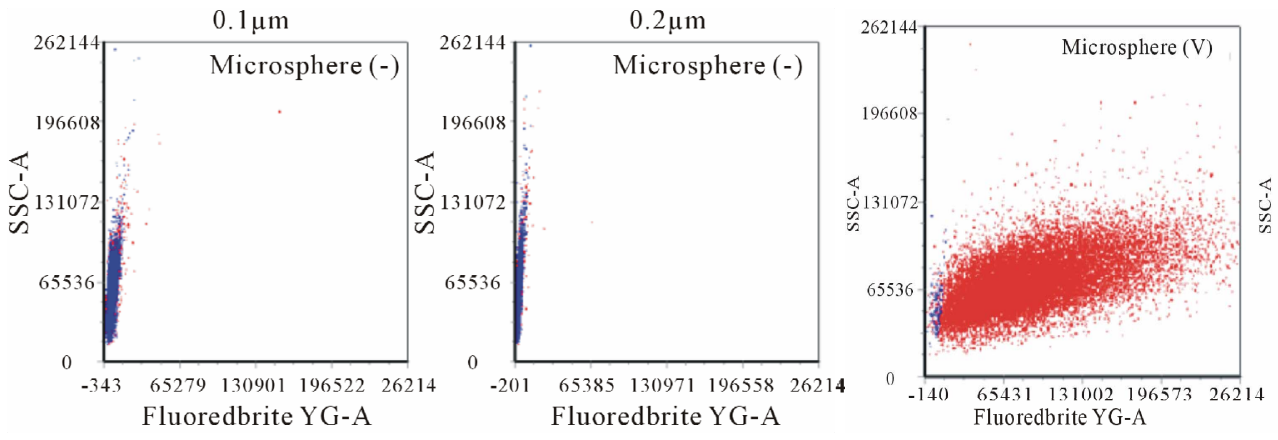

(b)
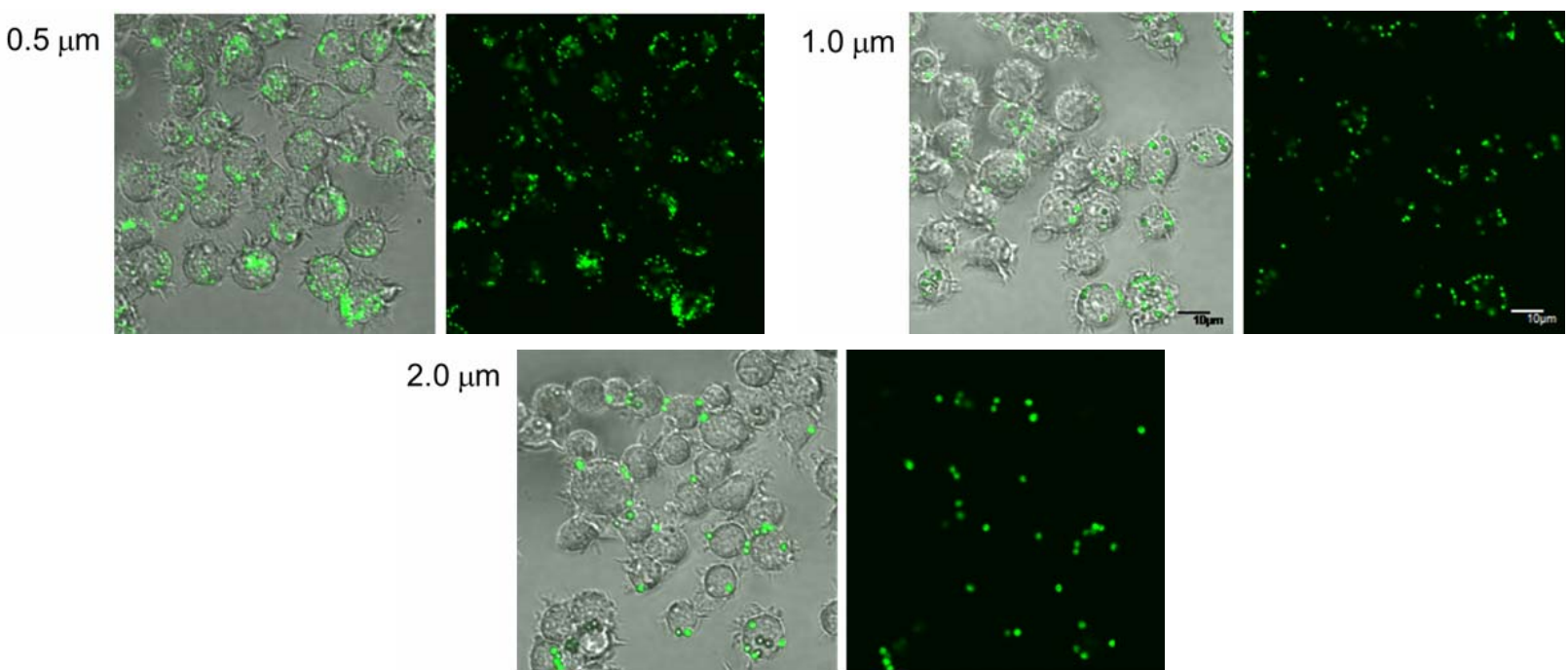

(c)

Figure 5. Phagocytosis by J774.1 macrophages when different sizes of microspheres were added at equal total volumes. Cells were incubated with different sizes of microspheres according to upper section of Table 1 for $1 \mathrm{~h}$. (a and b) Cells were washed 3 times and analyzed using a flow cytometer. (c) Cells were ob- served using a confocal laser scanning microscope after flow cytometry analysis.

cytized microspheres was measured. Cells phagocytized 0.1 or $1.0 \mu \mathrm{m}$ green or red microspheres (Figure 7(b)). Before phagocytosis, the presence of intracellular microspheres did not affect subsequent phagocytic activity and was independent of microsphere size. J774.1 cells retained phagocytic activity for $24 \mathrm{~h}$ after the first phagocytosis. Subsequently, J774.1 cells underwent repeated cell division along with microspheres, and the number of microspheres in the cells decreased because of repeated distribution to cells (data not shown). Although cell death of macrophages after phagocytosis of silica microspheres has been reported [9-11], the presence of intracellular polystyrene microspheres had no effect on cell viability or phagocytosis, which is the most basic cell function of macrophages used in this study.

\section{CONCLUSION}

Our results show that macrophages can phagocytize 0.1 $6.0-\mu \mathrm{m}$ polystyrene microspheres, demonstrating the importance of standardizing the amount of microspheres added to cells when evaluating phagocytosis. The amount or weight of microspheres added per culture area in phagocytic assays is often arbitrary. The addition of a 

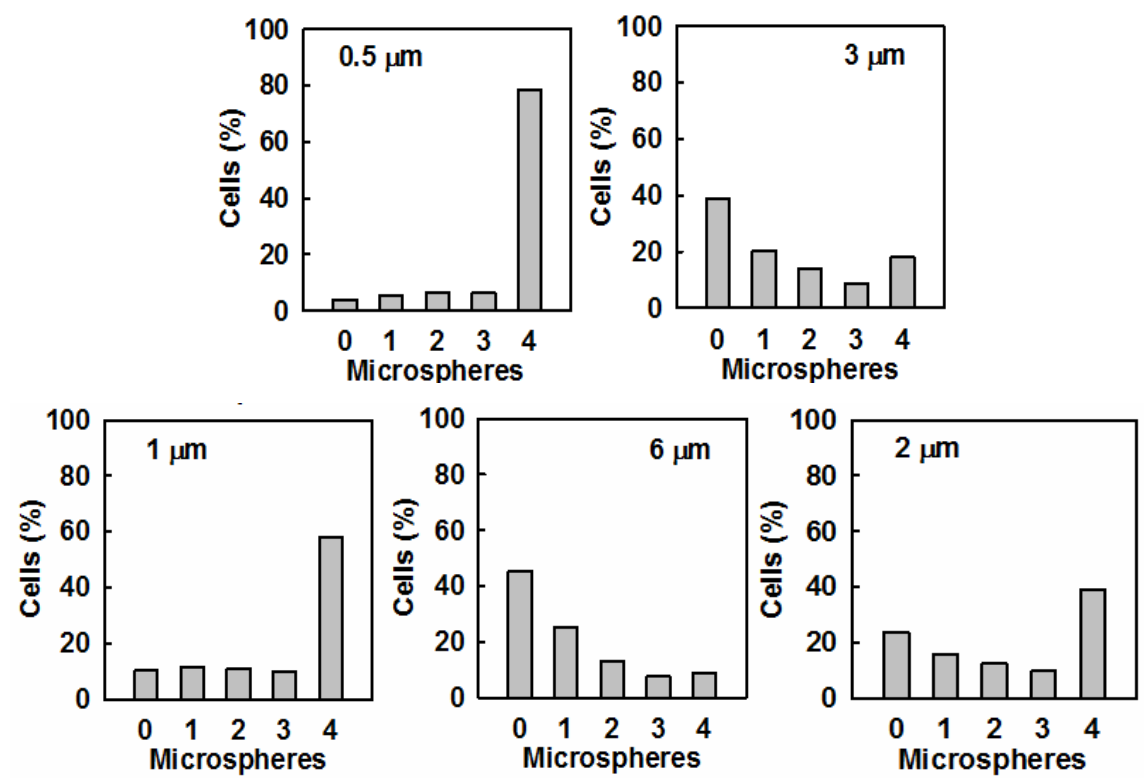

(a)
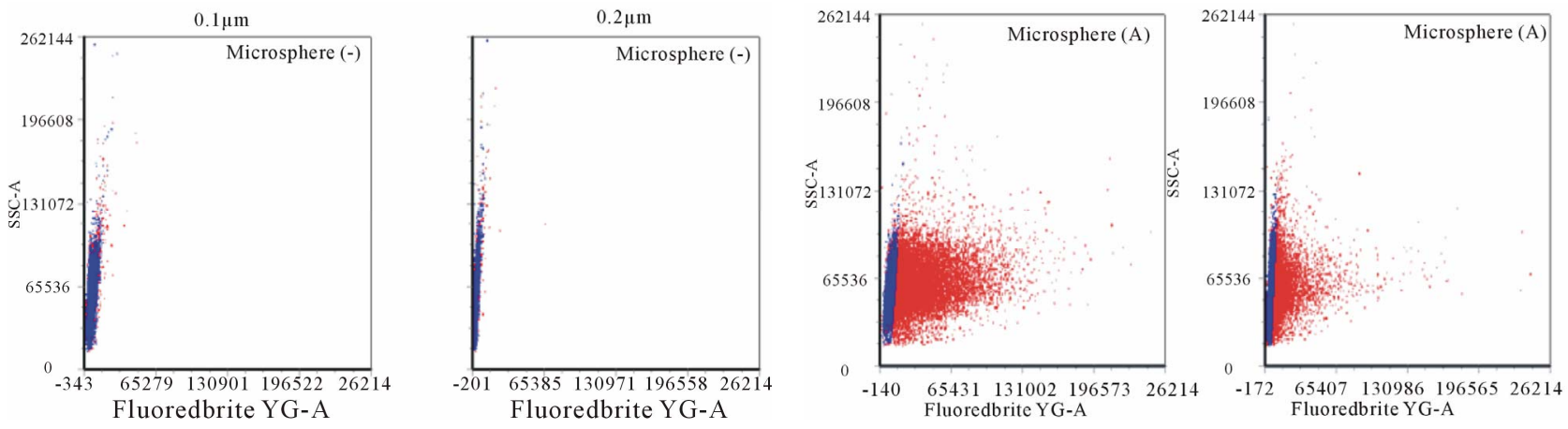

(b)
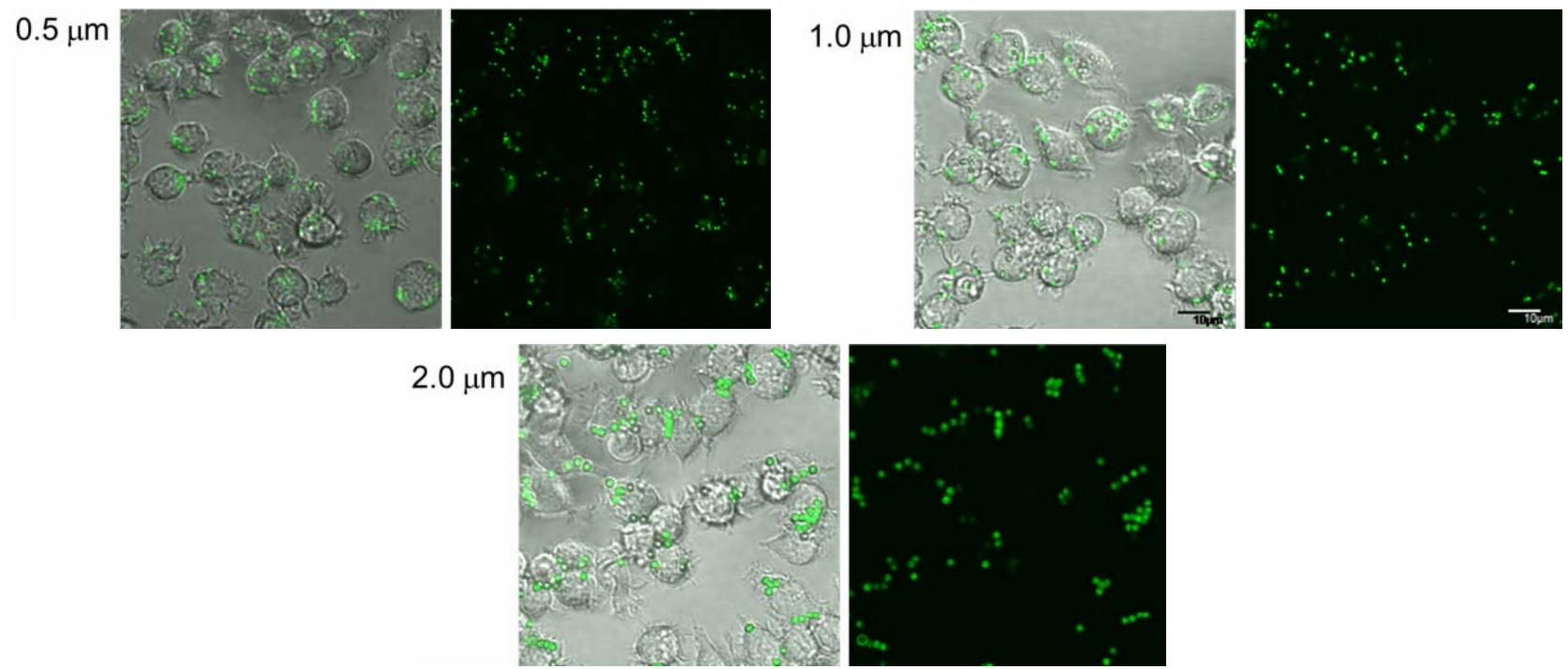

(c)

Figure 6. Phagocytosis by J774.1 macrophages when different sizes of microspheres were added at equal total surface areas. Cells were incubated with different sizes of microspheres according to lower section of Table 1 for $1 \mathrm{~h}$. (a and b) Cells were washed 3 times and analyzed using a flow cytometer. (c) Cells were observed using a confocal laser scanning microscope after flow cytometry analysis. 

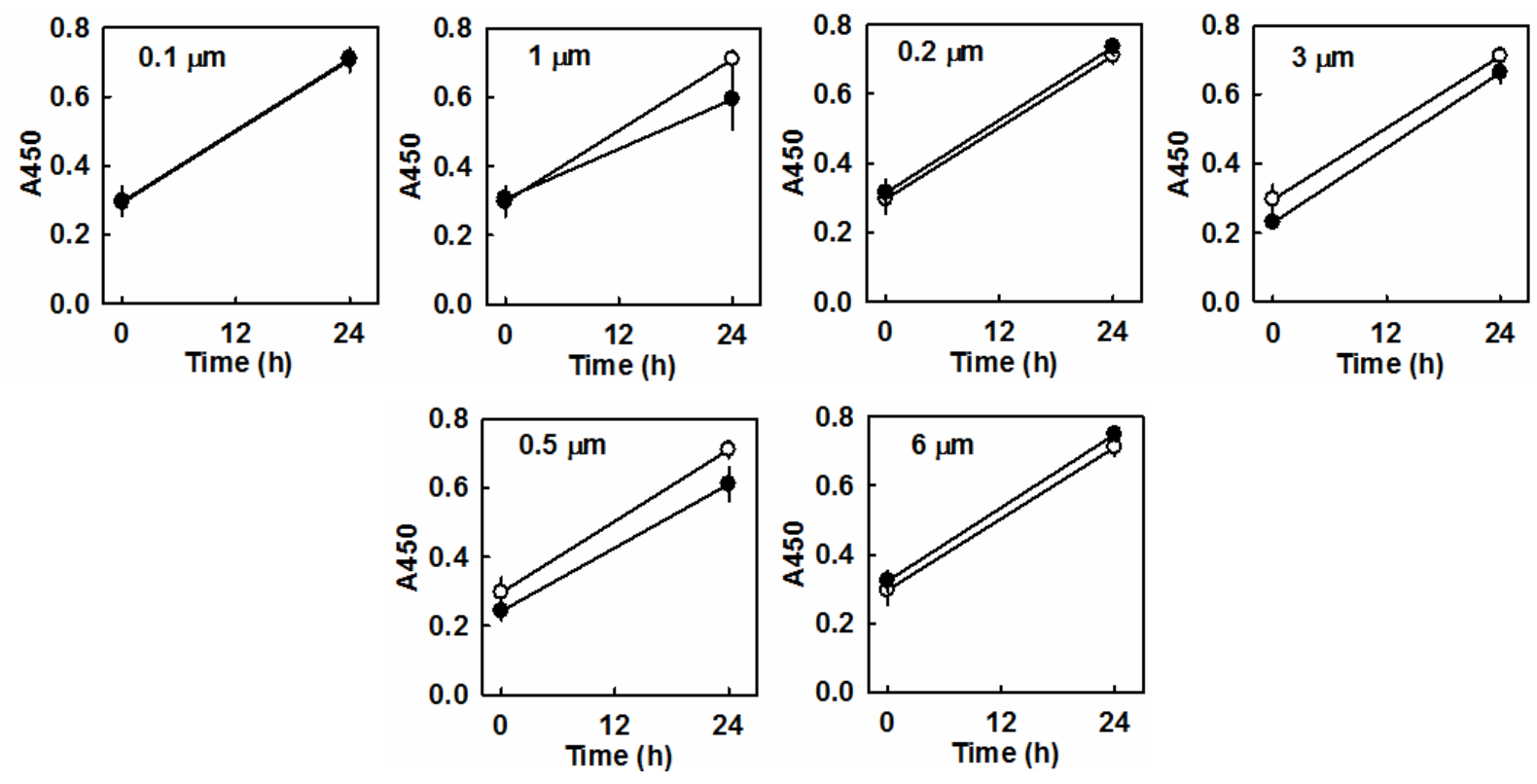

(a)
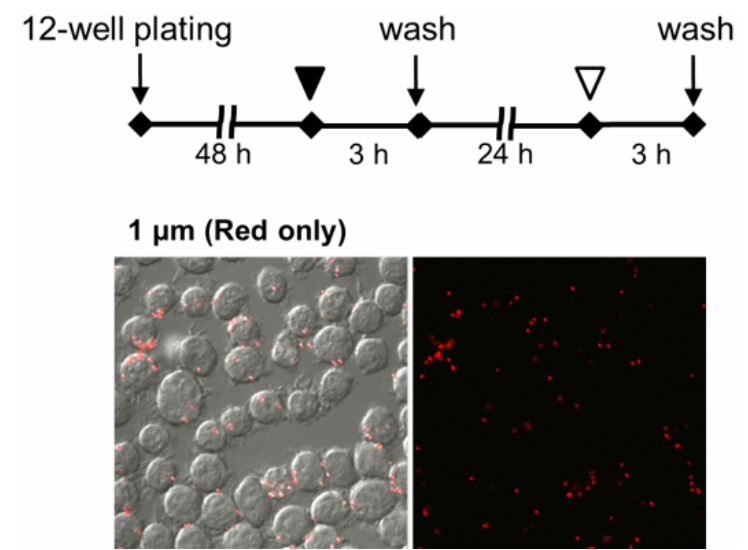

\section{$0.1 \mu \mathrm{m}$ (Green) $+1 \mu \mathrm{m}$ (Red)}
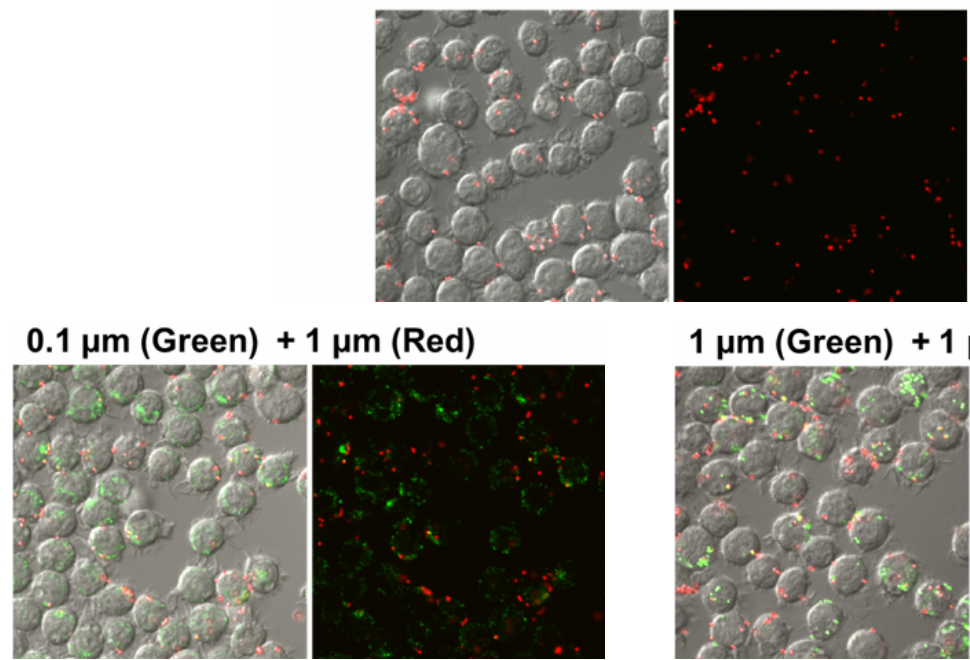

$1 \mu \mathrm{m}$ (Green) $+1 \mu \mathrm{m}($ red)

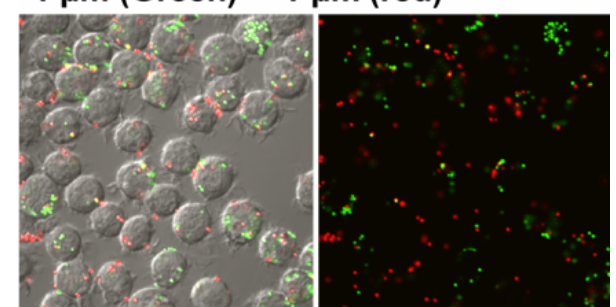

(b)

Figure 7. Effects of phagocytosis on cell viability, proliferation and phagocytic activity in J774.1 macrophages. (a) Cells were incubated with or without different sizes of microspheres for $3 \mathrm{~h}$. At the end of incubation, cells were washed and some were re-incubated in fresh growth medium for $24 \mathrm{~h}$. Cell survival immediately and $24 \mathrm{~h}$ after phagocytosis was determined by CCK- 8 assay. Open circle, control cell; closed circle, cells incubated with various sizes of microspheres. (b) Cells were incubated with or without 0.1 - or $1-\mu \mathrm{m}$ green fluorescent microspheres (closed triangles) for $3 \mathrm{~h}$ and then washed. Cells were then re-incubated in fresh growth medium for $24 \mathrm{~h}$ after which they were incubated with $1-\mu \mathrm{m}$ red fluorescent microspheres (open triangles) for $3 \mathrm{~h}$. Cells were observed by confocal laser scanning microscopy.

given amount of microspheres per culture area seems to be an orderly method, but this may be inappropriate for evaluation of phagocytosis of varying sizes of microspheres. On the other hand, the addition of a set weight per culture area complicates evaluation of phagocytosis of the same size of microspheres having different specific gravities. Our suggestion of a standardized method is better than the traditional methods in the evaluation of 
phagocytosis. Additionally, the polystyrene microspheres which are taken up in these conditions have no effect on cell viability or basic cell function.

\section{ACKNOWLEDGEMENTS}

This work was supported by the MEXT-Supported Program for the Strategic Research Foundation at Private Universities, 2012-2017.

\section{REFERENCES}

[1] Savill, J. (1998) Apoptosis. Phagocytic docking without shocking. Nature, 392, 442-443. http://dx.doi.org/10.1038/33025

[2] Shanbhag, A.S., Jacobs, J.J., Black, J., Galante, J.O. and Glant, T.T. (1994) Macrophage/particle interactions: Effect of size, composition and surface area. Journal of Biomedical Materials Research, 28, 81-90. http://dx.doi.org/10.1002/jbm.820280111

[3] Smith, A.M., Duan, H., Mohs, A.M. and Nie, S. (2008) Bioconjugated quantum dots for in vivo molecular and cellular imaging. Advanced Drug Delivery Reviews, 60, 1226-1240. http://dx.doi.org/10.1016/j.addr.2008.03.015

[4] Sulahian, T.H., Imrich, A., Deloid, G., Winkler, A.R. and Kobzik, L. (2008) Signaling pathways required for macrophage scavenger receptor-mediated phagocytosis: Analysis by scanning cytometry. Respiratory Research, 9, 59. http://dx.doi.org/10.1186/1465-9921-9-59

[5] Wu, Y.C. and Horvitz, H.R. (1998) C. elegans phago- cytosis and cell-migration protein CED-5 is similar to human DOCK180. Nature, 392, 501-504.

http://dx.doi.org/10.1038/32195

[6] Olynyk, J.K., et al. (1994) Differential production of TNF by Kupffer cells after phagocytosis of E. coli and C. albicans. American Journal of Physiology, 267, G213G219.

[7] Heneweer, C., Gendy, S.E. and Penate-Medina, O. (2012) Liposomes and inorganic nanoparticles for drug delivery and cancer imaging. Therapeutic Delivery, 3, 645-656. http://dx.doi.org/10.4155/tde.12.38

[8] Kreyling, W.G., Semmler-Behnke, M., Takenaka, S. and Moller, W. (2013) Differences in the Biokinetics of inhaled nano- versus micrometer-sized particles. Accounts of Chemical Research, 46, 714-722. http://dx.doi.org/10.1021/ar300043r

[9] Costantini, L.M., Gilberti, R.M. and Knecht, D.A. (2011) The phagocytosis and toxicity of amorphous silica. PLoS One, 6, e14647.

http://dx.doi.org/10.1371/journal.pone.0014647

[10] Gilberti, R.M., Joshi, G.N. and Knecht, D.A. (2008) The phagocytosis of crystalline silica particles by macrophages. American Journal of Respiratory Cell and Molecular Biology, 39, 619-627. http://dx.doi.org/10.1165/rcmb.2008-0046OC

[11] Joshi, G.N. and Knecht, D.A. (2013) Silica phagocytosis causes apoptosis and necrosis by different temporal and molecular pathways in alveolar macrophages. Apoptosis, 18, 271-285. http://dx.doi.org/10.1007/s10495-012-0798-y 